\title{
The relationship between the effects of UV light and thermal shock on gametes and the viability of early developmental stages in a marine teleost fish, the sea bass (Dicentrarchus labrax L.)
}

\author{
ALICIA FELIP, FRANCESC PIFERRER †, MANUEL CARRILLO \& SILVIA ZANUY* \\ Consejo Superior de Investigaciones Cientificas (CSIC), Instituto de Acuicultura de Torre la Sal, \\ 12595 Ribera de Cabanes, Castellón, Spain
}

\begin{abstract}
To improve the efficiency of gynogenetic induction, the effects of UV light and thermal shock on gametes were investigated in the sea bass. Exposure of sperm to UV light $\left(\geq 15000 \mathrm{erg} \mathrm{mm}^{-2}\right)$ reduced the amount of motile spermatozoa, without affecting the duration of motility in the spermatozoa that remained motile. The Hertwig effect was elicited in eggs fertilized with sperm exposed to $\geq 35000 \mathrm{erg} \mathrm{mm}^{-2}$ of UV light, indicating the inactivation of the DNA of the spermatozoa while retaining their ability to trigger development. Resulting embryos (24 chromosomes; one NOR) exhibited the haploid syndrome and died at hatch. Diploidy was restored in eggs fertilized with irradiated sperm by blocking meiosis II with a thermal shock $\left(0 \pm 0.5^{\circ} \mathrm{C}\right.$ for $10 \mathrm{~min}$, starting $5 \mathrm{~min}$ after fertilization). Resulting larvae ( $\sim 35 \%$ survival at hatching) had 48 chromosomes, one or two NOR and no paternal chromosome fragments (gynogenetic diploids). In eggs fertilized with sperm not exposed to UV light, the same thermal shock induced 100\% triploidy ( 72 chromosomes; one, two or three NOR), with $70 \%$ survival at hatching. Multifactorial ANOva showed that, compared to external factors (sperm diluent, UV light and thermal shock), the contribution of broodstock to the viability of the early developmental stages was not significant $(P>0.05)$. Effects of the thermal shock were most evident after fertilization $(30.7 \%)$ but disappeared $(0 \%)$ at hatching, suggesting that the lower survival of triploids is a consequence of handling, not of the triploid condition per se. However, effects of UV light increased through development (42.5-69.7\%), probably reflecting cumulative deficits in protein synthesis.
\end{abstract}

Keywords: Dicentrarchus labrax, gynogenesis, haploid syndrome, Hertwig effect, sex-determination, UV-irradiation.

\section{Introduction}

Fish, by virtue of their high fecundity, external fertilization and ability to tolerate manipulations of their chromosome sets, are suitable models in which to study some aspects of genetics (cytogenetics, sex determination). In addition, the production of polyploid fish and fish with uniparental inheritance (triploids and gynogenetics, respectively) has had a significant impact in the aquaculture of various species (Thorgaard, 1983).

\footnotetext{
*Correspondence. E-mail: zanuy@iats.csic.es

$\dagger$ Present address: Consejo Superior de Investigaciones Científicas (CSIC), Institut de Ciències del Mar, Passeig Joan de Borbó, s/n, 08039 Barcelona, Spain.
}

Gynogenetic fish have been used for the rapid production of inbred lines, for gene-centromere mapping (Ihssen et al., 1990), for the study of single-locus effects (Ihssen et al., 1990), as well as in studies aiming at the elucidation of the sex determination mechanism in fish (Mair et al., 1991). More recently, they have been used for the production of transgenics by gene transfer in 'incomplete gynogenesis' (Thorgaard et al., 1992, 1997).

To produce gynogenetic fish, eggs are usually fertilized with sperm in which DNA has been previously inactivated. In this manner, the spermatozoa's genetic material does not contribute to the genome of the resulting zygote, which is then haploid. Because haploids are not normally viable beyond hatching, diploidy is restored by preventing completion of meiosis II, by 
blocking the extrusion of the eggs' second polar body, or by blocking cleavage during the first mitotic division. To achieve this, usually a thermal or pressure shock is applied to eggs shortly after fertilization (Thorgaard, 1983). A drawback is that gynogenetic diploids exhibit low viability, presumably not only because of their higher homozygosity, but also as a consequence of the required manipulations of the gametes. This low viability is already apparent during the early developmental stages (i.e. fertilization, embryogenesis and hatching).

To inactivate the paternal DNA, sperm is most commonly exposed to ultraviolet (UV) light after dilution with an appropriate medium to facilitate irradiation (Chourrout, 1982). However, it is possible that UV light also affects the swimming performance of spermatozoa, thus diminishing their capacity to fertilize the eggs and trigger embryonic development. In this regard, it has been shown that UV light affects the tubulin bands of flagella in other flagellated cells (Häder, 1993). However, in the induction of gynogenesis, the effects of UV light on sperm motility are not usually examined and thus lower viability, also a consequence of lower fertilization, cannot be excluded. Furthermore, to ensure complete inactivation of sperm DNA and thus exclusive maternal inheritance, the Hertwig effect needs to be initially elicited. In this effect, a partial inactivation of the DNA occurs at low UV doses, resulting with increasing doses in progressively lower survival during embryogenesis, because of the aneuploid condition and the accumulation of recessive deleterious mutations. However, there is a certain UV dose range at which survival at embryogenesis increases despite the fact that survival at hatching continues to decrease (the Hertwig effect). This indicates complete inactivation of DNA, resulting in embryos that live through embryogenesis (they are more viable than aneuploids) but die at hatching because of their haploid condition (Thorgaard, 1983). The Hertwig effect has been reported in many teleost fish (Ijiri \& Egami, 1980; Chourrout, 1982; Onozato \& Yamaha, 1983; Don \& Avtalion, 1988; Valcárcel et al., 1994; Pongthana et al., 1995). The importance of eliciting the Hertwig effect is that it identifies the lowest dose of UV light (thus avoiding potential effects on sperm motility) that results in complete DNA inactivation. Eggs fertilized with sperm irradiated with this dose should have a haploid chromosome number, which can then be duplicated to restore diploidy.

In order to induce gynogenesis, gametes need to be exposed to several manipulations: dilution and irradiation of sperm to inactivate DNA, artificial fertilization of eggs and thermal or hydrostatic shock to restore diploidy in the zygote. These external factors undoubtedly have a bearing on subsequent survival. In addi- tion, the origin of broodstock also influences survival. However, to the best of our knowledge, in ploidy manipulation experiments the contribution of broodstock and external factors to early survival has not been clearly analysed and quantified in any fish. Hence, the low viability during early development of gynogenetic fish has traditionally been explained as the consequence of manipulations, ploidy level and inbreeding, but no attempts to quantify the relevance of each type of factor have been made. Without these data it is difficult to ascertain what part of the low viability of gynogenetic fish early in development is caused by the gynogenetic condition per se (i.e. higher homozygosity), the broodstock, or the external manipulations. This is particularly relevant in marine fish with small, fragile larvae because survival during early development, even in the absence of manipulations, is already low, and yields of gynogenetic fish are typically quite poor. Thus, gynogenesis has been experimentally induced mostly in freshwater species, particularly cyprinids and salmonids and only in a few marine species (see Solar et al., 1991; for review).

The sea bass (Dicentrarchus labrax L.) is a marine teleost distributed from the coasts of Norway and Northern Ireland to the Mediterranean, very important in fisheries and aquaculture in Europe, and the subject of research in many laboratories. In aquaculture, the production of all-female or sterile stocks is desirable, because this species exhibits sexually related dimorphic growth in favour of females and most male fish are matured before marketing (Carrillo et al., 1995a). Thus, it would be very interesting to know the sex determination mechanism in this species to attempt to bring it under our control. However, in spite of intensive research including cytological characterization (Sola et al., 1993), progeny testing of crosses between normal and sex-reversed females and the recent attempt to develop probes for putative sex-specific DNA sequences (Martínez et al., 1997), the sex determination mechanism in this species is not yet clear. The production of large quantities of gynogenetic sea bass and the later examination of their sex ratios might be useful to elucidate their sex determining mechanism, as has been achieved in other species (Mair et al., 1991). Preliminary studies in sea bass (Zanuy et al., 1994; Carrillo et al., 1995b; Colombo et al., 1995; Gorshkova et al., 1995) have demonstrated the possibility of producing gynogenetic diploids, although the yield so far has been very low.

In this study, the effects of UV light on sperm motility were first investigated in the sea bass. The Hertwig effect was then elicited to establish the appropriate UV dose to use in order to inactivate sperm DNA while retaining capacity of the sperm to trigger development. 
Next, gynogenetic haploids, gynogenetic diploids and triploids were produced and their survival was compared with that of appropriate control diploids. In this manner, the contribution of the broodstock and of external factors (sperm diluent, UV light and thermal shock) was quantified at different stages during early development. Finally, using an optimized treatment, diploidization of haploid gynogenetic zygotes was also shown to be effective with large volumes of eggs, resulting in diploid meiogynogenetic sea bass. These procedures could be useful for both basic and applied research.

\section{Materials and methods}

\section{Source of gametes}

Broodstock Dicentrarchus labrax were maintained in our facilities under natural conditions of photoperiod and temperature. During the reproductive season (January-February), female broodstock were intraovarically cannulated to determine the state of oocyte development. Spermiating males and females with postvitellogenic oocytes (average 700-800 $\mu$ m diameter) were injected with $5 \mu \mathrm{g} \mathrm{kg}^{-1}$ body weight (BW) of LHRHa (Syndel Laboratories, Vancouver, B.C., Canada). Four hours later, only females were injected with a second dose of $10 \mu \mathrm{g} \mathrm{kg}^{-1} \mathrm{BW}$. This treatment increases the amount of expressible milt produced in males and induces final oocyte maturation and ovulation in females (Zanuy et al., 1994; Carrillo et al., 1995b). A small sample of ovulated oocytes $(\sim 1.2 \mathrm{~mm}$ diameter $)$ was obtained three days later from each female by gentle abdominal massage and separately fertilized with an aliquot of sperm obtained from one randomly selected injected male. Sperm is usually suitable for fertilization during the reproductive season. Nevertheless, the quality of the eggs was estimated by the floatability of the fertilized eggs and by the symmetry of divisions $2-3 \mathrm{~h}$ postfertilization. Only eggs of good quality were used in the subsequent experiments.

\section{Experiment 1: Effects of UV light on sperm motility}

Sperm was diluted 1:10 with an appropriate diluent for sea bass sperm (100 mM NaCl, $13.4 \mathrm{~mm} \mathrm{KCl,} 26.2 \mathrm{~mm}$ $\mathrm{NaHCO}_{3}$ and $83.2 \mathrm{~mm}$ glycine, $\mathrm{pH}$ 7.35) (Carrillo et al., 1995b). Two millilitres of diluted sperm were placed in a glass Petri dish (9 $\mathrm{cm}$ diameter), forming a film $\sim 0.3 \mathrm{~mm}$ thick. The UV source consisted of four G15T8 $15 \mathrm{~W}$ lamps with max. emission at $254 \mathrm{~nm}$ (Sylvania, Tokyo). The lamps were switched on for half an hour before the experiment to stabilize the energy of the UV rays (Onozato \& Yamaha, 1983). Lamps were placed above the Petri dish and incident radiation at the sperm surface was measured with a UV-meter (UltraViolet Products, Inc., San Gabriel, CA). During exposure to UV light the Petri dish was maintained on ice and gently agitated with an orbital shaker. After irradiation, sperm was transferred to a glass vial, protected from ambient light and maintained on ice. Sperm motility and duration of the movement were then monitored microscopically according to Chambeyron \& Zohar (1990) and Sorbera et al. (1996), respectively.

\section{Experiment 2: The Hertwig effect}

The objective of this experiment was to determine the amount of UV light required to inactivate the DNA of the sperm while retaining the ability to fertilize the egg and trigger embryonic development. To elicit the Hertwig effect, eggs were obtained from the female with the best quality egg sample, as determined above, and divided into eight equal batches. Six were fertilized with aliquots of sperm previously exposed to different doses of UV light (2500-55000 erg $\mathrm{mm}^{-2}$ ). The other two were used as controls: (i) eggs fertilized with undiluted and nonirradiated sperm (control of gamete quality) and (ii) eggs fertilized with diluted and nonirradiated sperm (control of diluent effect). Artificial fertilization was performed at $13 \pm 1{ }^{\circ} \mathrm{C}$ using $4 \mathrm{~mL}$ of diluted sperm per each $100 \mathrm{~mL}$ of eggs. After fertilization, each batch was immediately divided into six groups of $\sim 300$ eggs each to determine survival in triplicate at two different times (see the 'Determination of survival' section below), and incubated at $16 \pm 1{ }^{\circ} \mathrm{C}$ as described previously (Felip et al., 1997).

\section{Experiment 3: Combined effects of UV light and thermal shock during meiosis II}

The objective of this experiment was to evaluate the effect of UV light and thermal shock applied alone or in combination to sperm and newly fertilized eggs, respectively, on the viability of the sea bass embryos and larvae. Good quality eggs were divided into six equal batches and the following groups were made: (i) untreated, diploid group, fertilized with undiluted sperm (control of gamete quality); (ii) diploid group, fertilized with diluted sperm (effect of diluent); (iii) triploid group, fertilized with undiluted sperm (effect of thermal shock); (iv) triploid group, fertilized with diluted sperm (effect of diluent + thermal shock); (v) haploid group, fertilized with diluted and irradiated sperm (effect of diluent + UV light); and (vi) gynogenetic diploid group, fertilized with diluted and irradiated sperm, and thermally shocked to restore diploidy (effect of diluent + UV light + thermal shock). Each group was subdivided into 12 groups of $\sim 300$ eggs to determine survival in 
triplicate groups at four different times postfertilization (see the 'Determination of survival' section below). Based on the results of expt 2, sperm was exposed to $35000-40000 \mathrm{erg} \mathrm{mm}^{-2}$ of UV light. Inhibition of meiosis II by preventing the extrusion of the second polar body was accomplished by a thermal shock at $0^{\circ} \mathrm{C}$, for $10 \mathrm{~min}$, starting $5 \mathrm{~min}$ after fertilization (Felip et al., 1997). Preshock incubation temperature was $13 \pm 1{ }^{\circ} \mathrm{C}$. Eggs were incubated as described previously (Felip et al., 1997).

\section{Experiment 4: Diploidization of a large number of haploid meiogynogenetic zygotes}

Based on the results of expts 2 and 3, restoration of diploidy was achieved in a large volume of eggs from one female. Batches of $175-250 \mathrm{~mL}$ of eggs $(1 \mathrm{~mL}$ $\sim 750$ eggs) were fertilized with irradiated sperm and subsequently exposed to a thermal shock as described above (gynogenetic group). A similar amount of eggs were fertilized with diluted sperm not exposed to UV light (control group). Each group was incubated in 200-L closed system aquaria provided with slowflowing, filtered, UV-sterilized and aerated sea water. Control diploid and gynogenetic diploid larvae were reared in duplicate under standard procedures for sea bass.

\section{Determination of survival}

Survival was expressed as a percentage of the number of eggs fertilized. In expt 2 , survival was calculated: (i) at $48 \mathrm{~h}$ postfertilization (HPF), as percentage embryogenesis, and (ii) at $72 \mathrm{HPF}$, as the number of newly hatched normal larvae (percentage hatching). In expt 3, survival was calculated at four developmental stages: (i) at 24 HPF as percentage fertilization; (ii) at $48 \mathrm{HPF}$ as percentage embryogenesis; (iii) at $72 \mathrm{HPF}$ as the number of newly hatched larvae (percentage hatching); and (iv) at $96 \mathrm{HPF}$ as the number of surviving larvae. In both experiments, survival was determined in triplicate at each time. In expt 4 , survival could not be calculated accurately but, as predicted, lower viability was observed in the gynogenetic diploids than in the control diploids.

\section{Determination of ploidy}

Ploidy was determined by analysis of the nucleolar organizing regions (NOR) and by karyotyping, as described previously (Felip et al., 1997). In expt 2, ploidy was determined at $72 \mathrm{HPF}$ in newly hatched larvae from the control group fertilized with diluted sperm and the group whose sperm was irradiated at
$35000 \mathrm{erg} \mathrm{mm}^{-2}$ (12 larvae/treatment). In expt 3, 12 larvae/treatment between 72 and 96 HPF were used. In expt 4, 12 larvae from the control group and the gynogenetic groups were used to verify ploidy 3-64 days postfertilization.

\section{Statistical analysis of data}

Experiments 1 and 3 were carried out three times whereas expts 2 and 4 were conducted twice. Only experiments in which the percentage hatching was $\geq 23 \%$ in the control groups were considered. Percentage survival was arc sintransformed before statistical analysis. In expt 1, sperm motility was calculated as mean \pm SEM from three different experiments with three replicates in each UV dose treatment. Percentage of motility was arc sin transformed before statistical analysis. Analysis of variance (ANOVA) was used to compare treatment effects on motility as well as duration of motility among different doses of UV light. In expt 2 , in order to eliminate variability between batches, survival was expressed relative to that of the control group fertilized with diluted sperm, for which the percentage of embryogenesis at $48 \mathrm{HPF}$ was set at $100 \%$. In expt 3, survival was expressed relative to that of the diploid control group fertilized with undiluted sperm, in which the percentage of fertilization was set at 100\% (Felip et al., 1997). Analysis of variance (ANOvA) was used to compare treatment effects on survival among different experimental groups. Data from expt 3 were used in a multifactorial ANOVA analysis to determine the effect of each treatment on the viability in the different early developmental stages. Differences were accepted as significant when *.

\section{Results}

In expt 1, the effect of UV light on sperm motility was determined after activation with sea water and immediate observation under the microscope. Results (Table 1) show that doses of $15000 \mathrm{erg} \mathrm{mm}^{-2}$ or higher significantly $(*)$ decreased the amount of motile sperm from class IV (72.2-80\% motile) to class II $(27.2-48.3 \%$ motile). However, the duration of motility was not statistically different between control and UV-exposed sperm, regardless of dose (Table 1).

In expt 2, aliquots of control and UV-exposed sperm were separately added to batches of normal eggs. In the control groups, the use of the diluent increased survival although not in a statistically significant manner $(50.4 \pm 2.39 \%$ vs. $40.6 \pm 4.06 \%$ at $48 \mathrm{HPF}$, and $27.8 \pm 4.78 \%$ vs. $23.2 \pm 5.79 \%$ at $72 \mathrm{HPF}$ ). In the groups fertilized with UV-exposed sperm, percentage surviving embryos at $48 \mathrm{HPF}$ and normal larvae at 72 HPF decreased with increasing doses from 2500 to 
Table 1 Motility of sea bass spermatozoa after exposure to different doses of UV light

\begin{tabular}{lcc}
\hline $\begin{array}{l}\text { Dose of UV light } \\
\left(\mathrm{erg} \mathrm{mm}^{-2}\right)\end{array}$ & $\begin{array}{c}\text { Sperm motility } \\
\text { class } \dagger\end{array}$ & $\begin{array}{c}\text { Duration of } \\
\text { motility } \\
(\mathrm{min})\end{array}$ \\
\hline $0\left(\mathrm{Control}^{+}\right)$ & $72.2 \pm 1.47$ (IV) & $2.99 \pm 0.51$ \\
$0\left(\mathrm{Control}^{++}\right)$ & $80.0 \pm 0.00$ (IV) & $3.51 \pm 0.52$ \\
2500 & $70.0 \pm 0.00$ (IV) & $3.45 \pm 0.41$ \\
15000 & $60.0 \pm 0.00$ (III)* & $2.97 \pm 0.36$ \\
25000 & $48.3 \pm 0.00$ (II)* & $3.04 \pm 0.32$ \\
35000 & $40.0 \pm 2.89$ (II)* & $2.55 \pm 0.34$ \\
45000 & $40.0 \pm 2.89$ (II)* & $2.62 \pm 0.36$ \\
55000 & $27.2 \pm 3.64$ (II)* & $2.53 \pm 0.37$ \\
\hline
\end{tabular}

Abbreviations: $\mathrm{Control}^{+}$, fertilized with undiluted sperm; Control $^{++}$, fertilized with sperm diluted $1: 10$. $\dagger$ Evaluation scale from ( 0 to V) according to Chambeyron \& Zohar (1990) and

$\$$ according to Sorbera et al. (1996). * Significantly different from Control $^{+}(*)$.

$25000 \mathrm{erg} \mathrm{mm}^{-2}$ (Fig. 1). However, at doses of $\geq 35000$ erg $\mathrm{mm}^{-2}$ whereas percentage survival of larvae was $\leq 3.5 \%$ at $72 \mathrm{HPF}$, survival during embryogenesis at $48 \mathrm{HPF}$ increased up to $45.4 \%$ with respect to previous assayed doses $(P>0.05)$. These results are typical of a Hertwig effect. Thus, 35 000-40 000 erg $\mathrm{mm}^{-2}$ of UV light was considered a suitable dose to inactivate DNA in sea bass sperm while maintaining the ability to activate egg development.

Embryos (Fig. 2a) and hatched larvae (Fig. 2b) from the diploid, control groups had a morphologically normal appearance, with cells containing one or two NOR (Fig. 3a) and 48 chromosomes (Fig. 3b), as expected. In contrast, embryos originating from eggs fertilized with sperm exposed to $35000 \mathrm{erg} \mathrm{mm}^{-2}$ of UV light exhibited aberrant development (Fig. 2c). The few larvae that hatched were deformed, exhibiting a typical 'haploid syndrome' (Fig. 2d). The haploid condition of these larvae was verified and it was found that they had only one NOR (Fig. 3c) and 24 chromosomes (Fig. 3d). No aneuploid or mosaic individuals were observed.

The outcome of expt 3 is shown in Fig. 4. Groups fertilized with sperm not exposed to UV light and thermally shocked shortly after fertilization had one, two or three NOR per cell and 72 chromosomes (not shown), indicating that they were indeed triploids, as previously demonstrated (Felip et al., 1997). Groups fertilized with sperm exposed to UV light and thermally shocked had one or two NOR per cell (Fig. 3e) and 48 chromosomes (Fig. 3f). External morphology was similar to control diploids (Fig. 2e,f). Consistent with previous observations, the control diploids fertilized with diluted sperm (Fig. 4b) had higher survival at $24 \mathrm{~h}$

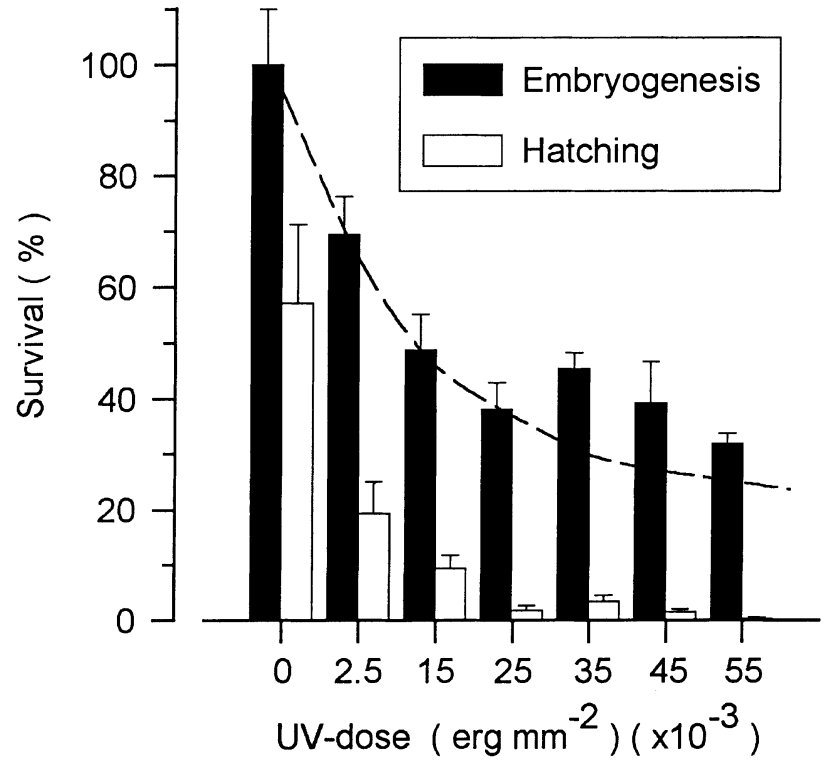

Fig. 1 Representation of a typical Hertwig effect curve in the sea bass. Survival of fertilized eggs at two different times during early ontogenesis: embryogenesis (48 HPF) and hatching (72 HPF) is shown as a function of the dose of UVirradiation applied to different aliquots of the sperm used for fertilization. The sperm was diluted $1: 10$ prior to irradiation. Each data point is the mean \pm SEM of two separate experiments with triplicate determinations for each dose. The dotted line indicates expected survival at $48 \mathrm{HPF}$ when extrapolated from lower $\left(\leq 25000 \mathrm{erg} \mathrm{mm}^{-2}\right)$ to higher $\left(\geq 35000 \mathrm{erg} \mathrm{mm}^{-2}\right.$ ) doses of UV light. Differences between expected and observed survival with doses $\geq 35000 \mathrm{erg} \mathrm{mm}^{-2}$ evidence a typical Hertwig effect.

after fertilization as compared to the diploid group fertilized with undiluted sperm (Fig. 4a). A similar effect was also observed in triploids (compare Fig. 4c,d). These differences, however, were not statistically significant. Within groups, survival of morphologically normal embryos or larvae progressively decreased with development, from fertilization to one day posthatch, but ANOvA failed to detect significant differences in all groups but the triploids made with diluted sperm (Fig. 4d) and the haploids (Fig. 4e), where survival at embryogenesis and onwards was significantly different from survival after fertilization.

Between groups, marked differences were evident in those in which eggs were fertilized with sperm exposed to UV light, regardless of the final ploidy level (Fig. 4e,f). In haploids, survival after fertilization was similar to that of nonirradiated groups but significantly (*) decreased during embryogenesis, with less than 5\% morphologically normal larvae remaining at hatching and onwards (Fig. 4e). In the gynogenetic diploids (Fig. 4f), survival after fertilization was similar to that 


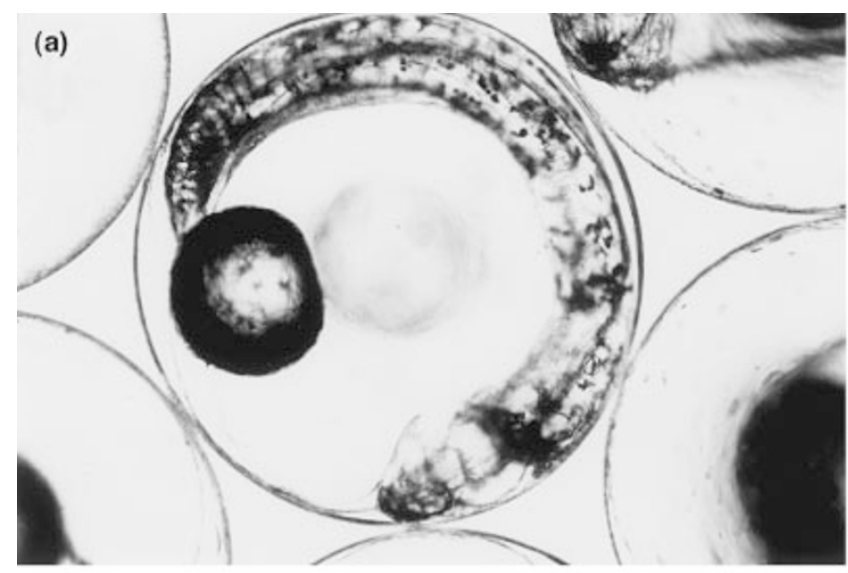

(b)

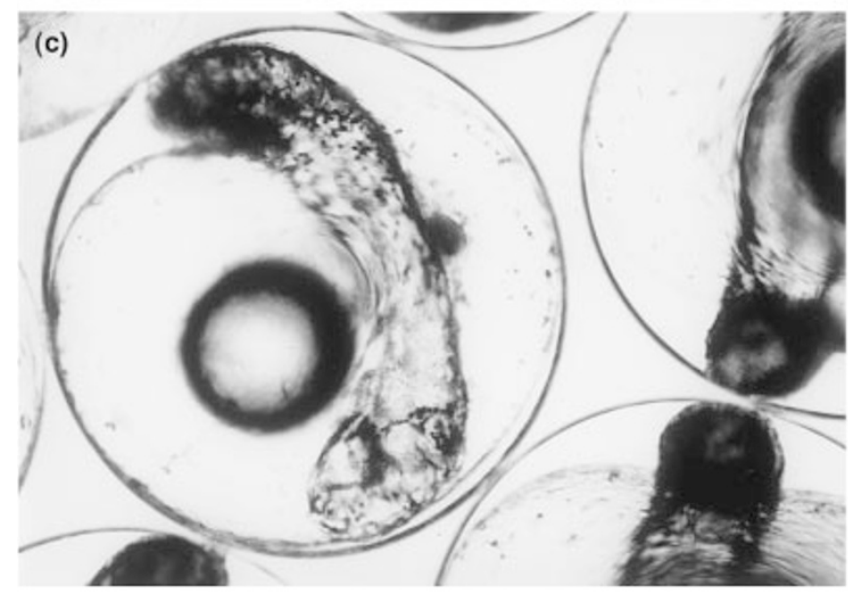

(d)
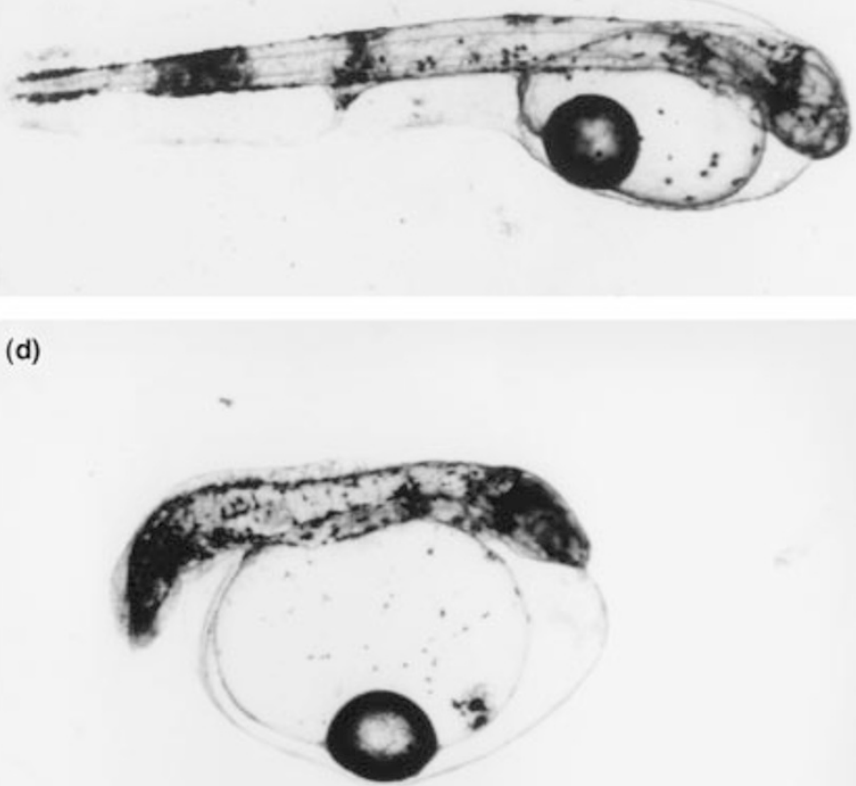

(e)

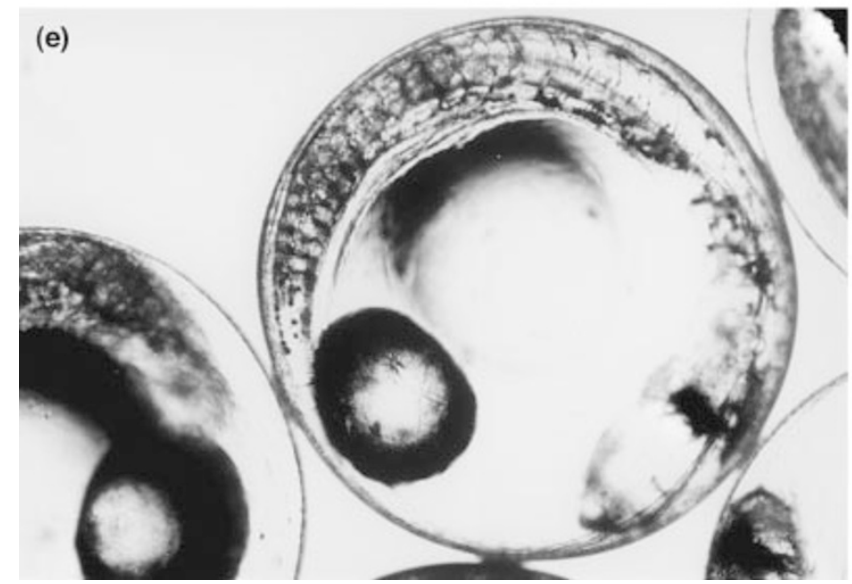

(f)

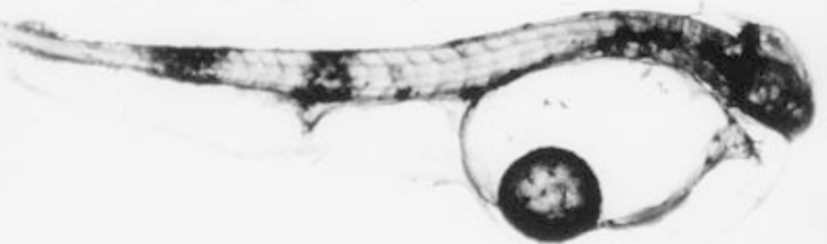

Fig. 2 External morphology of diploid (a, b), haploid (c, d) and meiogynogenetic diploid (e, f) sea bass embryos at $48 \mathrm{~h}$ postfertilization (HPF) and larvae at $72 \mathrm{HPF}$.

of other experimental groups except the diploids made with diluted sperm. However, survival during embryogenesis and onwards was not significantly different from survival of groups that received a thermal shock (compare Fig. 4f with Fig. 4c,d) but different from survival of diploids fertilized with diluted sperm (com- pare with Fig. 4b) and different from survival of diploids fertilized with normal sperm at one day posthatching (Fig. 4a).

Regarding external morphology, diploid and triploid groups had a similar percentage of normal embryos and larvae $(P>0.05)$. The gynogenetic diploids had a lower

(C) The Genetical Society of Great Britain, Heredity, 83, 387-397. 
Fig. 3 Determination of ploidy in the sea bass at $72 \mathrm{HPF}$. Ag-stained nucleolar organizing regions (NOR) and chromosome preparations of diploid $(\mathrm{a}-\mathrm{b})$, haploid (c-d) and meiogynogenetic diploid larvae (e-f).
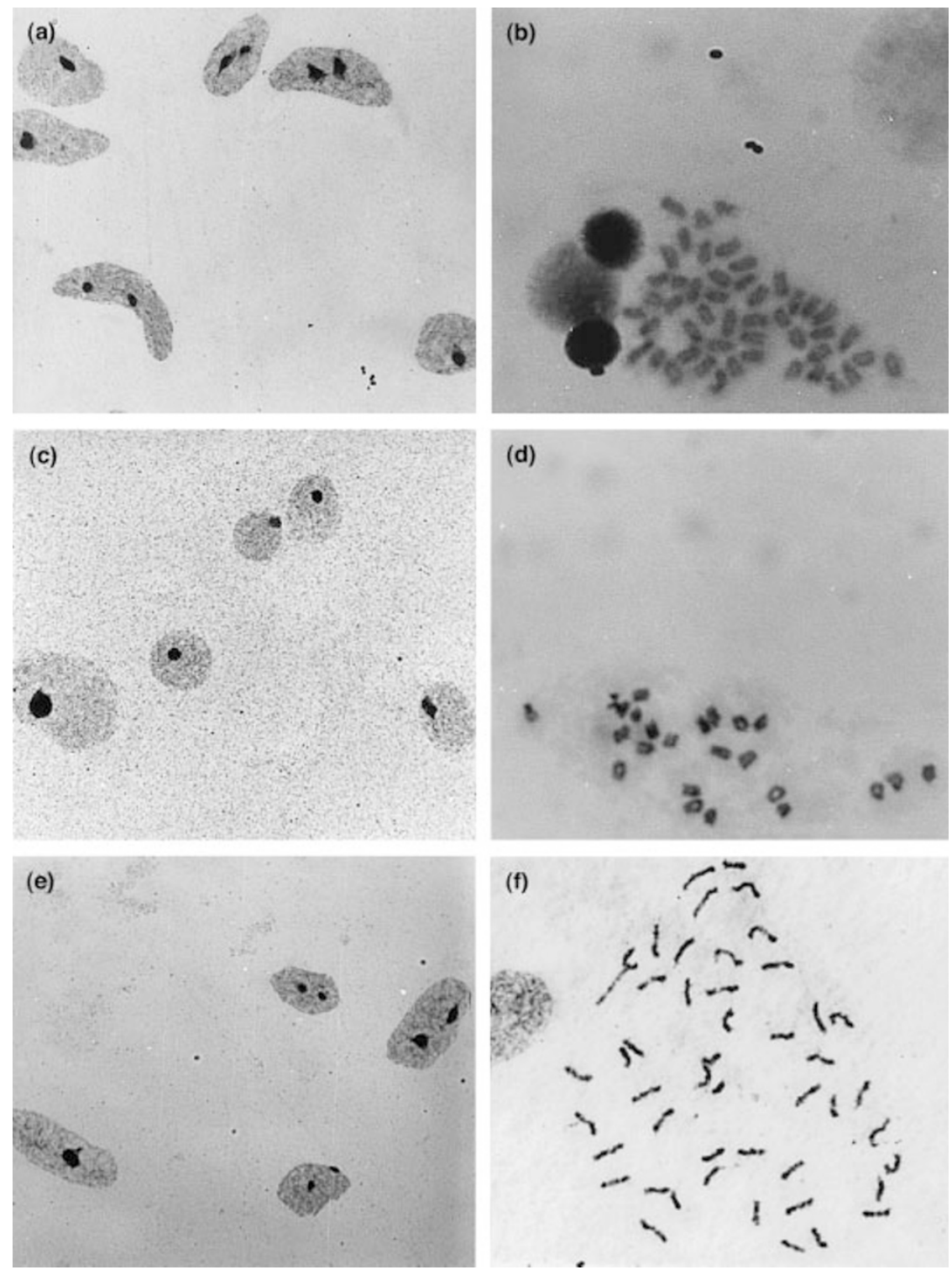

percentage of surviving normal individuals, different from that of the diploids fertilized with diluted sperm, at all stages, and from the diploids fertilized with undiluted sperm only at $96 \mathrm{HPF}(*)$ but similar to the triploids $(P>0.05)$. In all groups but the haploids, percentage deformed larvae at $96 \mathrm{HPF}$ was similar. In the haploids, most embryos at $48 \mathrm{HPF}$ and larvae at $96 \mathrm{HPF}$ were deformed.

Table 2 shows the contribution that the pair of broodstock, male and female, used in each repetition of each experiment and environmental factors, applied alone or combined (i.e. sperm diluent, UV light and thermal shock), had on the viability of the early developmental stages of sea bass. Results show that the fish chosen from broodstock and the sperm diluent did not significantly influence survival. In contrast, using
UV-exposed sperm for fertilization and thermally shocking eggs shortly after fertilization contributed, approximately, half and one-third, respectively, to the survival after fertilization $(*)$. Thereafter, the contribution of the effect of UV light increased to $\sim 70 \%$ at one day posthatch, whereas the contribution of the thermal shock disappeared by the time of hatching.

Consistent with data from expts 2 and 3, successful diploidization of sea bass haploid gynogenetic embryos was achieved by activation of sea bass eggs with sperm exposed to UV light at a dose range between 35000 and $40000 \mathrm{erg} \mathrm{mm}^{-2}$ and subsequently applying a thermal shock at $0^{\circ} \mathrm{C}$ for $10 \mathrm{~min}$, starting 5 min after fertilization. Morphological examination, NOR analysis and karyotyping (one or two NOR; 48 chromosomes) showed that the embryos and hatching larvae were

(C) The Genetical Society of Great Britain, Heredity, 83, 387-397. 
diploids, as predicted. Up to 5 months of age, the growth performance of gynogenetic diploid sea bass was similar to that of their control diploids, and thus no significant differences were found between diploids and gynogenetic diploids in weight ( $3.48 \pm 0.18$ vs. $3.40 \pm 0.18 \mathrm{~g})$ and in length $(6.28 \pm 0.13$ vs. $6.0 \pm 0.13 \mathrm{~cm})$.

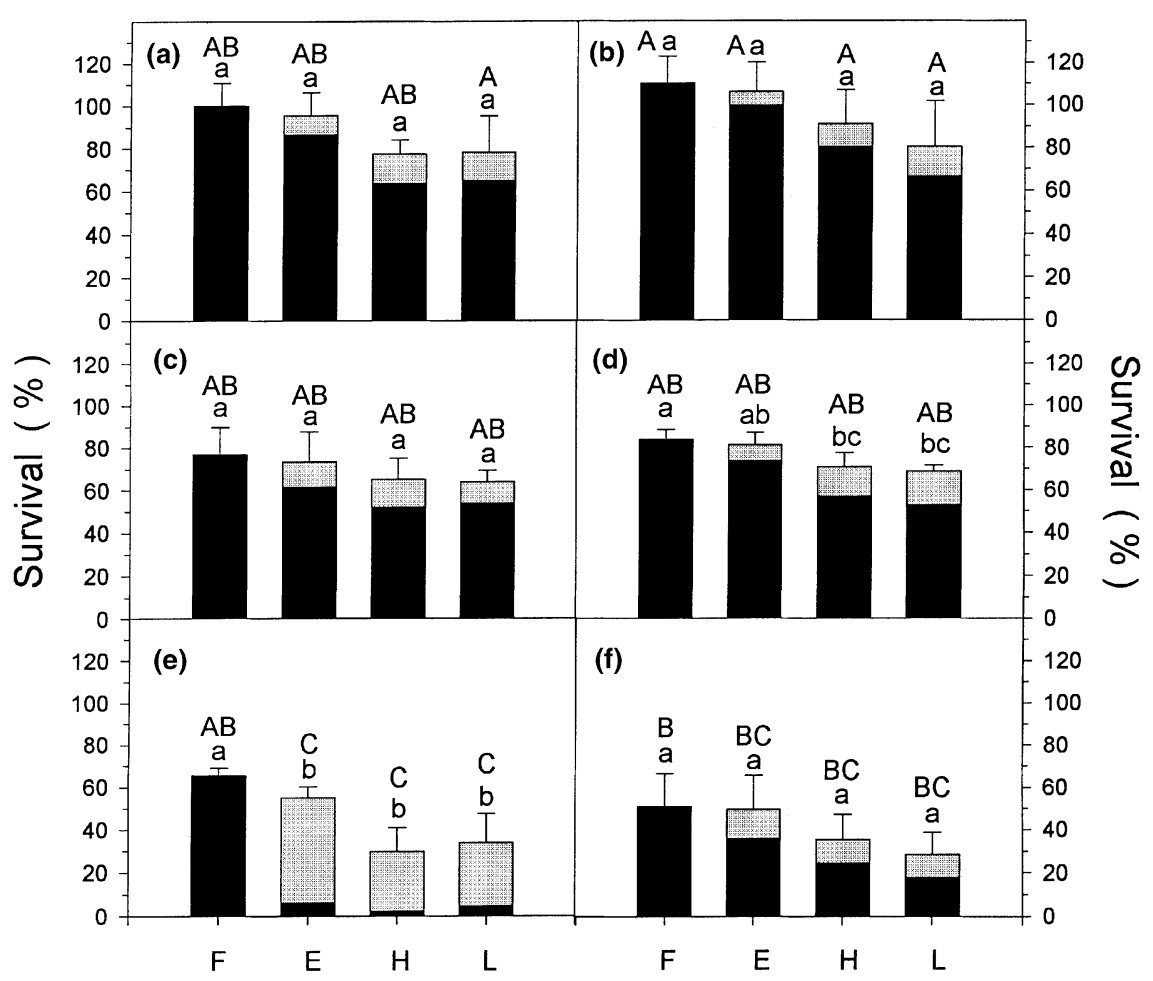

Fig. 4 Effect of various types of gamete manipulations, applied alone or in combination, on the viability of the sea bass during early developmental stages: fertilization, 24 HPF (F); embryogenesis, 48 HPF (E); hatching, 72 HPF (H); and one day posthatch, 96 HPF (L). (a) Untreated, diploid group made with undiluted sperm (control of gamete quality, with survival at fertilization set to $100 \%$, to which all the other treatments and groups were compared). Actual survival at F was $61.8 \pm 6.7 \%$; (b) diploid group made with diluted sperm (effect of diluent); (c) triploid group made with undiluted sperm (effect of thermal shock); (d) triploid group made with diluted sperm (effect of diluent + thermal shock); (e) haploid group made with diluted and irradiated sperm (effect of diluent + UV light); and (f) gynogenetic diploid group made with diluted and irradiated sperm and thermally shocked to restore diploidy (effect of diluent + UV light + thermal shock). Data as mean \pm SEM of three separate experiments, with triplicate determination for each data point. The lengths of bars indicate survival, with the black portion of a bar referred to the proportion of morphologically normal individuals and the shaded part of a bar referred to deformed individuals. Upper case letters indicate significant $(*)$ differences in survival between groups at the same developmental stage. Lower case letters indicate significant $(*)$ differences in survival between different developmental stages within each group.

Table 2 Contribution of the studied factors to survival of sea bass during early development

\begin{tabular}{|c|c|c|c|c|c|c|c|c|c|c|c|c|c|c|c|c|}
\hline \multirow{2}{*}{$\begin{array}{l}\text { Source of } \\
\text { variation } \\
\text { Main effects }\end{array}$} & \multicolumn{4}{|c|}{$\begin{array}{l}\text { Fertilization } \\
(24 \mathrm{HPF})\end{array}$} & \multicolumn{4}{|c|}{$\begin{array}{c}\text { Embryogenesis } \\
\text { (48 HPF) }\end{array}$} & \multicolumn{4}{|c|}{$\begin{array}{l}\text { Hatching } \\
(72 \mathrm{HPF})\end{array}$} & \multicolumn{4}{|c|}{$\begin{array}{c}\text { One day posthatch } \\
(96 \mathrm{HPF})\end{array}$} \\
\hline & $\mathrm{C}$ & d.f. & $F$ & & $\mathrm{C}$ & d.f. & $F$ & & $\mathrm{C}$ & d.f. & $F$ & & $\mathrm{C}$ & d.f. & $F$ & \\
\hline Broodstock & 7.1 & 2 & 2.2 & NS & 5.3 & 2 & 1.1 & NS & 4.6 & 2 & 1.1 & NS & 3.5 & 2 & 1 & NS \\
\hline Sperm diluent & 0.6 & 1 & 0.4 & NS & 3.1 & 1 & 1.3 & NS & 2.2 & 1 & 1.1 & NS & 0 & 1 & 0 & NS \\
\hline UV light & 43 & 1 & 27 & $*$ & 47 & 1 & 20 & $*$ & 69 & 1 & 34 & $*$ & 70 & 1 & 36 & $*$ \\
\hline
\end{tabular}

$* P<0.05$. Abbreviations: $\mathrm{C}$, percentage contribution; HPF, hours postfertilization. 


\section{Discussion}

This study investigated and quantified the effects of external factors, such as sperm diluent, UV light and thermal shock, applied alone or in combination to gametes, and their relationship with the viability of successive early developmental stages in a marine teleost. Appropriate controls, triplicate determinations of survival at each stage and repetition of experiments were included in the experimental design to compensate the fragility of marine fish larvae and thus avoid distorting effects on survival data.

Exposure of sperm to UV light reduced the amount of motile spermatozoa but, remarkably, did not affect the duration of motility in the remaining motile spermatozoa, implying that the effects of UV light on individual spermatozoa are of the all-or-none type. These results were probably not because of the manner in which sperm was irradiated, i.e. motile spermatozoa were not spermatozoa that escaped radiation, for two reasons. First, during exposure, the sperm was diluted 1:10, occupying a layer of $\sim 0.3 \mathrm{~mm}$, and continuously agitated in order to ensure successful penetration of UV light. Secondly, although some diploid fish were found in the treatment group expected to contain only haploids, thus suggesting that a few spermatozoa might indeed have escaped exposure to UV light, the number of diploid fish in the haploid group was always $<5 \%$. This percentage is in sharp contrast to the amount of motile spermatozoa even in the samples that received the highest doses of UV light, which was $20-50 \%$. Thus, there was a higher proportion of motile spermatozoa than diploid larvae in the haploid group, suggesting that the motile spermatozoa were sperm with inactivated DNA by the formation of thymine dimers (Tyrell, 1986). Reduced motility at increasing UV-doses has been reported in both freshwater green flagellates and marine dinoflagellates (Häder, 1986). Effects on decreased motility were demonstrated to be the consequence of damage to tubulin bands, affecting equally and progressively the whole cell population (Häder, 1993). Thus, to our knowledge, all-or-none effects as described here have not been reported previously and the significance of this deserves further attention.

A typical 'Hertwig effect' was observed when sperm exposed to increasing doses of UV light was used for fertilization. In the present study, the 2500-55000 erg $\mathrm{mm}^{-2}$ range was explored and it was found that the Hertwig effect occurred at doses $\geq 35000 \mathrm{erg} \mathrm{mm}^{-2}$ using sperm diluted $1: 10$. This was consistent with the results of Zanuy et al. (1994) and Carrillo et al. (1995b), who found decreasing survival at hatching with doses up to $30000 \mathrm{erg} \mathrm{mm}^{-2}$; and with the results of Colombo et al. (1995), who observed that meiogynogenetic sea bass could be produced after exposure to UV-doses 10 times lower than the ones used here but with sperm diluted 1 : 100 (i.e. 10 times our dilution). Here it should be mentioned that $35000-40000 \mathrm{erg} \mathrm{mm}^{-2}$ allowed not only a sufficient proportion of motile spermatozoa to maintain the fertilization capacity but also very few spermatozoa escaped irradiation as deduced from the low number of diploid fish in the haploid group. In addition, no chromosome fragments were observed in the karyotypes of the resulting larvae. The observation that sperm dilution increased the ability to fertilize eggs is in agreement with the results of Carrillo et al. (1995b), who showed the usefulness of this diluent for artificial fertilization of sea bass, a species with dense sperm as compared with other fish.

Survival in early developmental stages was examined in relation to ploidy and previous history of gamete manipulation. Abnormal embryos and larvae were found in all groups, including the controls. This may indicate that the presence of deformities is a consequence of handling during artificial fertilization, or a result of inbreeding, because captive fish were used, or of chromosomal aberrations, which are observed also in wild fish (Colihueque et al., 1996). The percentage of abnormal larvae observed in diploids agreed with what is usually found in this species (Cerdá et al., 1994). However, abnormalities increased in the gynogenetic fish, especially in the haploids. This is likely to reflect their higher homozygosity compared to diploids (Leary et al., 1985; Don \& Avtalion, 1988). The presence of deleterious recessive lethal genes or the absence of normal genes in pairs in homologous or heterologous chromosomes may contribute to the very low viability of haploids (Varadaraj, 1993).

The rates of fertilization recorded in this study coincide with those reported for artificially fertilized sea bass, which are $\sim 50 \%$ (range 35-65\%). Other authors working with this species have reported survival at hatching of $27-43 \%$ in the diploids, $40-50 \%$ of controls in the triploids and $17-28 \%$ of controls in the gynogenetic diploids (Colombo et al., 1995; Gorshkova et al., 1995). In the present study, similar survival rates in diploids but substantially higher survival rates in triploids ( $\sim 70 \%$ of controls) and in gynogenetic diploids ( $\sim 35 \%$ of controls) were observed. Better survival of triploids and gynogenetic diploids is probably the consequence of using an optimized thermal shock to prevent the extrusion of the second polar body (Felip et al., 1997) and the appropriate dose of UV light to inactivate sperm as deduced from the Hertwig effect. These optimal conditions were demonstrated to be suitable to induce meiogynogenesis in a large volume of sea bass eggs. Karyological analysis resulted in 48 chromosomes and no chromosome fragments in the 
group fertilized with irradiated sperm and exposed to thermal shock, demonstrating that they were gynogenetic diploids. However, the true assessment of gynogenetic origin in individual fish can only be achieved by methods such as DNA fingerprinting, not used in the present study.

Under the present experimental paradigm, the source of the gametes (i.e. the use of a particular pair of broodstock) and the use of the sperm diluent had no significant bearing on survival of embryos during early development (Table 2). Nevertheless, fish chosen, particularly females, were selected based on the quality of the eggs. This does not imply that the broodstock component is not important but it shows that, when compared to external factors (UV light and thermal change), its contribution to survival is minor in this type of experiments.

The effects of the thermal shock were most evident in the hours following fertilization but quickly decreased through embryogenesis and disappeared by the time of hatching. This demonstrates that the usual lower yield of triploid larvae at hatching reflects a lower survival already evidenced after fertilization as a consequence of the physical stress imposed by the thermal shock. Thus, the lower survival of triploids early in development, frequently reported in the literature (see Ihssen et al., 1990; for review), is probably a consequence of handling and physical stress, not of the triploid condition per se.

The UV light was the external factor most important in terms of influencing the viability of early developmental stages and had an opposite effect when compared to that of the thermal shock. Thus, the effect of UV light was apparent already after fertilization and the magnitude of its contribution remained essentially the same during embryogenesis. However, at hatching and thereafter, the effect of UV light was still more pronounced. This is reflected in the temporary viability of haploid embryos, indicating that development progresses in the absence of half of the genome but cumulative deficits in protein synthesis become lethal at hatching. Thus, the lower hatchability of haploid embryos may reflect, in particular, lower synthesis of the hatching enzyme (Egami \& Ijiri, 1979).

In summary, by virtue of their natural external fertilization and by being able to withstand the induction of polyploidy and uniparental inheritance, fish are suitable models for the investigation of the effects of several external factors on the early viability of vertebrate embryos. In the present study, the magnitudes of these effects were quantified for the first time, and their consequences for early survival have been related to allelic contribution (gynogenesis) and genome size (triploidy). Furthermore, an optimized method to produce gynogenetic sea bass is presented. Because this species is easily reared in many laboratories across Europe, gynogenetic sea bass has the potential to be used as a tool in several fields of research.

\section{Acknowledgements}

We thank C. Marin and the Aquarium staff of the Instituto de Acuicultura de Torre de la Sal for technical assistance. We thank Dr J. Ramos for his assistance in the mass-production of gynogenetic diploids and Dra L. Sorbera for her help with English. Research supported by EC grant no. AIR2-CT93-1543 and by CICYT grant no. AGP94-1321-CE to S.Z. A.F. was supported by a predoctoral fellowship from the Generalitat Valenciana.

\section{References}

CARrillo, M., ZANUY, S., BLÁZQUEZ, M., RAMOS, J., PIFERRER, F. AND DONALDSON, E. M. 1995b. Sex control and ploidy manipulation in sea bass. In: Environmental Impacts of Aquatic Biotechnology, OECD documents, pp. 125-143. OECD, Paris.

CARRILlO, M., ZANUY, S., PRAT, F., CERDÁ, J., RAMOS, J., MAÑANÓS, E. AND BROMAGE, N. 1995a. Sea bass (Dicentrarchus labrax). In: Bromage, N. R. and Roberts, R. J., (eds) Broodstock Management and Egg and Larval Quality, pp. 138-168. Blackwell Science, Oxford.

CERDÁ, J., CARRILlO, M., ZANUY, S., RAMOS, J. AND DE LA HIGUERA, M. 1994. Influence of nutritional composition of diet on sea bass, Dicentrarchus labrax L., reproductive performance and egg and larval quality. Aquaculture, 128, 345-361.

CHAMBEYRON, F. AND ZOHAR, Y. 1990. A diluent for sperm cryopreservation of gilthead sea bream, Sparus aurata. Aquaculture, 90, 345-352.

CHOURrout, D. 1982. Gynogenesis caused by ultraviolet irradiation of salmonid sperm. J. Exp. Zool., 223, 175181.

COlihuEQUE, N., ITURRA, P., DÍAZ, N. F. AND VEloso, A. 1996. Further evidence of chromosome abnormalities in normal and haploid gynogenetic progenies of rainbow trout, Oncorhynchus mykiss. J. Exp. Zool., 276, 70-75.

COLOMBO, L., BARBARO, A., LIBERTINI, A., BENEDETTI, P., FRANCESCON, A. AND LOMBARDO, I. 1995. Artificial fertilization and induction of triploidy and meiogynogenesis in the European sea bass, Dicentrarchus labrax L. J. Appl. Ichthyol., 11, 118-125.

DON, J. AND AVTAlion, R. R. 1988. Production of $F_{1}$ and $F_{2}$ diploid gynogenetic tilapias and analysis of the 'Hertwig curve' obtained using ultraviolet irradiated sperm. Theor. Appl. Genet., 76, 253-259.

EGAMI, N. AND IJIRI, K. I. 1979. Effects of irradiation on germ cells and embryonic development in teleosts. Int. Rev. Cytol., 59, 195-248.

FELIP, A., ZANUY, S., CARRILlO, M., MARTíNEZ, G., RAMOS, J. AND PIFERRER, F. 1997. Optimal conditions for the induction 
of triploidy in the sea bass (Dicentrarchus labrax L.). Aquaculture, 152, 287-298.

GORShKovA, G., GORSHKOV, S., HADANI, A., GORDIN, H. AND KNIBB, w. 1995. Chromosome manipulations in marine fish. Aquaculture, 137, 157-158 (Abstract).

HÄDER, D. P. 1986. The effect of enhanced solar UV-B radiation on motile microorganisms. In: Worrest, R. C. and Caldwell, M. M. (eds) Stratospheric Ozone Reduction, Solar Ultraviolet Radiation and Plant Life, NATO ASI Series, Vol. G8, pp. 223-233. Springer, Berlin.

HÄDER, D. P. 1993. Risks of enhanced solar ultraviolet radiation for aquatic ecosystems. In: Round, F. E. and Chapman, D. J. (eds) Progress in Phycological Research, Vol. 9, pp. 1-45. Biopress Ltd, Bristol.

IHSSEN, P. E., MCKAY, L. R., MCMILLAN, I. AND PHILLIPS, R. B. 1990. Ploidy manipulation and gynogenesis in fishes: cytogenetic and fisheries applications. Trans. Am. Fish. Soc., 119, 698-717.

IJIRI, K. I. AND EGAMI, N. 1980. Hertwig effect caused by UVirradiation of sperm of Oryzias latipes (teleost) and its photoreactivation. Mutat. Res., 69, 241-248.

LEARY, R. F., ALLENDORF, F. W., KNUDSEN, K. L. AND THORGAARD, G. H. 1985. Heterozygosity and developmental stability in gynogenetic diploid and triploid rainbow trout. Heredity, 54, 219-225.

MAIR, G. C., SCOTT, A. G., PENMAN, D. J., BEARDMORE, J. A. AND SKIBINSKI, D. O. F. 1991. Sex determination in the Genus Oreochromis. 1. Sex reversal, gynogenesis and triploidy in O. niloticus (L.) Steindachner. Theor. Appl. Genet., 82, 144 152.

MARTÍNEZ, G., RODRÍGUEZ, L., CARRILlO, M. AND ZANUY, s. 1997. Attempts for the development of DNA probes to determine the genetic sex in the European sea bass (Dicentrarchus labrax L.) using subtractive hybridisation. In: Sixth International Symposium on Genetics in Aquaculture, 24-28 June 1997. Institute of Aquaculture, Stirling, Scotland (Abstr.).

ONOZATO, H. AND YAMAHA, E. 1983. Induction of gynogenesis with ultraviolet rays in four species of salmoniformes. Bull. Jap. Soc. Sci. Fish., 49, 693-699.

PONGTHANA, N., PENMAN, D. J., KARNASUTA, J. AND MCANDREW, B. J. 1995. Induced gynogenesis in the silver barb (Puntius gonionotus Bleeker) and evidence for female homogamety. Aquaculture, 135, 267-276.
SOLA, L., BRESSANELlO, S., ROSSI, A. R., IASELLI, V., CROSETTI, D. AND CATAudella, s. 1993. A karyotype of the genus Dicentrarchus by different staining techniques. J. Fish Biol., 43, 329-337.

SOlAR, I. I., DONALDSON, E. M. AND DOUVILlE, D. 1991. A bibliography of gynogenesis and androgenesis in fish (191389). Can. Tech. Rep. Fish. Aq. Sci., 1788.

SORBERA, L., MYLONAS, C. C., ZANUY, S., CARRILlO, M. AND ZOHAR, Y. 1996. Sustained administration of GnRHa increases milt, without altering sperm counts in the sea bass. J. Exp. Zool., 276, 361-368.

THORGAARD, G. H. 1983. Chromosome set manipulation and sex control in fish. In: Hoar, W. S., Randall, D. J. and Donaldson, E. M. (eds) Fish Physiology, Vol. IXB, pp. 405434. Academic Press, New York.

THORGAARD, G. H., ADAMS, K. J., BRUNELLI, J. P. AND WHEELER, P. A. 1997. DNA markers associated with introduced brook trout minichromosomes in transgenic rainbow trout. In: Sixth International Symposium on Genetics in Aquaculture, 24-28 June 1997. Institute of Aquaculture, Stirling, Scotland (Abstr.).

THORGAARD, G. H., SCHEERER, P. D. AND ZHANG, J. 1992. Integration of chromosome set manipulation and transgenic technologies for fishes. Mol. Mar. Biol. Biotech., 1, 251-256.

TYRELL, R. M. 1986. Repair of genetic damage induced by UVB (290-320 nm) radiation. In: Worrest, R. C. and Caldwell, M. M. (eds) Stratospheric Ozone Reduction, Solar Ultraviolet Radiation and Plant Life, NATO ASI Series, Vol. G8, pp. 139-149. Springer, Berlin.

VAlCÁrCEl, A., GUERrero, G. AND MAGgESE, M. C. 1994. Hertwig effect caused by UV-irradiation of sperm of the catfish, Rhamdia sapo (Pisces, Pimelodidae), and its photoreactivation. Aquaculture, 128, 21-28.

VARADARAJ, K. 1993. Production of viable haploid Oreochromis mossambicus gynogens using UV-irradiated sperm. J. Exp. Zool., 267, 460-467.

ZANuy, S., CARrillo, M., BlÁzQuez, M., RAmos, J., Piferrer, F. AND DONAldson, E. M. 1994. Production of Monosex and Sterile Sea Bass by Hormonal and Genetic Approaches, pp. 91-106. Association Devélopmentale Aquaculture, http://www.iats.csic.es. 